\title{
ELECTROPHORESIS
}

\section{Thermostatted Dual-Channel Portable Capillary Electrophoresis Instrument}

\begin{tabular}{|r|l|}
\hline Journal: & ELECTROPHORESIS \\
\hline Manuscript ID & elps.201600235.R1 \\
\hline Datey - Manuscript type: & Research Paper \\
\hline Complete List of Authors: & $\begin{array}{l}\text { Koenka, Joel } \\
\text { Küng, Nina } \\
\text { Kuban, Pavel; Inst. Anal. Chem. AS CR, Electromigration Methods } \\
\text { Chwalek, Thomas; EAWAG, } \\
\text { Furrer, Gerhard; ETH } \\
\text { Wehrli, Bernhard; Eawag } \\
\text { Müller, Beat; EAWAG, } \\
\text { Hauser, Peter; The University of Basel, Department of Chemistry }\end{array}$ \\
\hline Keywords: & Capillary Electrophoresis, Portable Instrument, Field Analysis \\
\hline & \multicolumn{2}{l}{} \\
\hline
\end{tabular}




\title{
Thermostatted Dual-Channel Portable Capillary Electrophoresis Instrument
}

\author{
Israel Joel Koenka ${ }^{1}$, Nina Küng ${ }^{2,3}$, Pavel Kubáńn ${ }^{4}$, Thomas Chwalek ${ }^{2}$, Gerhard Furrer ${ }^{3}$, \\ Bernhard Wehrli ${ }^{2}$ Beat Müller ${ }^{2}$, Peter C. Hauser ${ }^{1 *}$ \\ ${ }^{1}$ Department of Chemistry, University of Basel, Spitalstrasse 51, 4056 Basel, Switzerland \\ ${ }^{2}$ Eawag, Swiss Federal Institute of Aquatic Science and Technology, 6047, \\ Kastanienbaum, Switzerland \\ ${ }^{3}$ Institute of Biogeochemistry and Pollutant Dynamics, Department of Environmental \\ Systems Science, ETH Zurich, 8092 Zurich, Switzerland \\ ${ }^{4}$ Institute of Analytical Chemistry of the Czech Academy of Sciences, v. v. i., Veveři 97, \\ 60200 Brno, Czech Republic
}

*Corresponding author.

E-mail address: Peter.Hauser@unibas.ch (P. C. Hauser)

Phone: ++41612671003

Keywords: Capillary Electrophoresis, Portable devices, On-site measurements, Environmental monitoring

\begin{abstract}
Abbreviations: BGE, background electrolyte, PCR polymerase chain reaction, $\mathrm{HV}$, high voltage; $C^{4} \mathrm{D}$, capacitively coupled contactless conductivity detection; SIA, sequential injection analysis; PID, proportional-integral-derivative; PMMA, polymethylmethacrylate; HPLC, high performance liquid chromatography; PACE, pressure assisted capillary electrophoresis.
\end{abstract}




\begin{abstract}
A new portable capillary electrophoresis instrument is presented. The instrument features the concurrent separation of anions and cations in parallel channels. Each channel has a separate buffer container to allow independent optimization of separation conditions. The microfluidics circuit is based on off-the-shelf parts, and can be easily replicated; only four valves are present in the design. The system employs a miniature automated syringe pump, which can apply both positive and negative pressures (-100 to $800 \mathrm{kPa})$. The application of negative pressure allows a semi-automatic mode of operation for introducing volume-limited samples. The separations are performed in a thermostatted compartment for improved reproducibility in field conditions. The instrument has a compact design, with all components, save for batteries and power supplies, arranged in a briefcase with dimensions of $52 \times 34 \times 18 \mathrm{~cm}$ and a weight of less than $15 \mathrm{~kg}$. The system runs automatically and is controlled by a purpose-made graphical user interface on a connected computer. For demonstration, the system was successfully employed for the concurrent separation and analysis of inorganic cations and anions in sediment porewater samples from Lake Baldegg in Switzerland and of metal ions in a sample from the tailing pond of an abandoned mine in Argentina.
\end{abstract}




\section{Introduction}

On-site analysis is important when the results are required for time-critical decisions or if the samples are not stable. The logistics of an analytical campaign can also be significantly streamlined by field analysis. Capillary electrophoresis is well suited to mobile analysis tasks due to its inherent simplicity compared to other separation methods such as HPLC and ion-chromatography as well as its high versatility for different classes of ionic species. Portable capillary electrophoresis instruments have therefore gained in interest in the last few years. Successful examples include many diverse applications such as the determination of residues of improvised explosive devices [1-3], chemical warfare agent detection $[4,5]$, the detection of amphetamines in street drugs and urine of suspected users [6], the analysis of food samples [7-9], the detection of hydrazines in environmental samples [10], the determination of beta-agonists in pig feed [11], the analysis of volatiles in air samples (after absorption) with a mobile robotic system [12], organic acids including herbicides in environmental samples [13], DNA fragments [14], inorganic ions in urine, blood serum samples, or exhaled breath condensate $[15,16]$, as well as in environmental samples [17-22]. Portable CE has also been combined with portable PCR for the detection of viral infections [23], the identification of cattle breeds [24], and forensic purposes [25]. The topic of portable CE has been reviewed by Macka and coworkers in 2010 [26], in 2013 by Lewis et al. [27] and very recently by Van Schepdael [28].

A critical challenge for portable CE instruments is the injection. For benchtop instruments the most common approach is direct pressurization of the sample vial after having moved it to the capillary inlet. For a time, a commercial portable instrument was available, which incorporated a conventional sampling tray and hydrodynamic injection $[13,14]$. However, it appears that the company is no longer in business. For purpose made portable $\mathrm{CE}$ 
instruments which have been reported in the scientific literature other approaches have been adapted. The earliest such instruments relied on electrokinetic injection. This is the simplest approach [20-22], as the hardware for applying voltage is inherently available. It is not ideal however, as electrokinetic injection depends on the conductivity of the sample and therefore the results will be biased for varying sample matrices. Improvised siphoning injection by manually lifting the capillary, which is temporarily placed in the sample vial, has also often been used [17-19]. This does not require special hardware either, but the delicate procedure is difficult to carry out in the field. As the timing is manual the performance is highly dependent on the operator skill. Different approaches to improve sample injection for portable CE instruments have therefore been investigated. Kaljurand and coworkers investigated a syringe-based system, which employed a metering valve in the flow path to restrict and thereby control the flow of sample injected into the capillary $[1,5]$. Automated siphoning was recently introduced by Greguš et al. [15]. This system has the capillary end connected to an auxiliary tubing leading to a buffer container positioned about $10 \mathrm{~cm}$ lower than the inlet; the connection is opened and closed with a tube pinch valve for aspirating the sample at the other end. Hauser and coworkers have reported portable instruments based on pressurization of a buffer reservoir with compressed air and a valving system to achieve hydrodynamic injection [8, 29, 30]. However, these instruments required a relatively large sample volume, giving up one of the advantages of CE, namely its suitability for volume-limited samples.

Frequently, the determination of both, cations and anions, is desired in single samples. While there are several approaches for the concurrent determination of both kinds of ions, including dual-opposite end injection, the only one that allows an independent buffer 
selection for each channel is dual-channel CE. This has also been implemented in portable systems $[8,29,30]$.

For a portable $\mathrm{CE}$ instrument to work well under field conditions, care should be taken with regard to the effect of ambient temperature. CE results are temperature sensitive as all transport phenomena in liquid media depend on viscosity (hydrodynamic plug injection, electrophoretic migration, etc.), and even the detector signal itself varies with temperature. Shading from sunlight has therefore been recommended [19], e.g. by enclosing the separation section in an opaque box [15].

In this report, a new portable $\mathrm{CE}$ instrument employing a microfluidic breadboard approach based on miniature off-the-shelf parts [31] is presented, which addresses several of the points discussed above: (i) Injection is achieved using a miniature syringe pump, offering full automation when using positive pressure and semi-automation when using negative pressure for aspiration of volume-limited samples, (ii) the CE separations are carried out inside an actively thermostatted compartment, (iii) cations and anions are separated simultaneously in two distinct channels using individual BGEs. The performance of the new system was tested by the analysis of porewater samples extracted from lake sediment cores directly at the sampling site at Lake Baldegg in Switzerland, as well as from a tailing pond of an abandoned mine in Argentina.

\section{Materials and methods}

\subsection{Instrumentation}

The briefcase containing the system was sourced from Farnell (Duratool, TC-1, Farnell, Zug, Switzerland). The rechargeable lithium battery packs (Turnigy nano-tech $5000 \mathrm{mAh}$ 
4S) and battery charger (IMAX B6-AC Charger/Discharger 1-6 Cells) were obtained from Hobby King (Hong Kong). The foldable solar panel (Solarset Ampera 17V/78W SCR) was purchased from SIStech (Zurich, Switzerland). The high voltage modules (UM30*4) were products from Spellman (Pulborough, UK). The contactless conductivity detectors (ER225B, EA120 amplifier and two capillary head stages ET120) were obtained from eDAQ (Denistone East, NSW, Australia). Note, that this was a special set-up, which had been modified for battery operation and the accommodation of two detector cells. The electropherograms were acquired with the Chart software package from eDAQ. The fluid handling manifold was assembled from parts obtained from LabSmith (Livermore, CA, USA). This included a microfluidic breadboard (uPB-05), a $100 \mu \mathrm{L}$ syringe pump (SPS01), 3-way valves (AV201), a pressure sensor (uPS0800-T116), interconnects (T116203) and reservoirs (T116-BBRES). Connections were made with 1/16" OD and 0.01" ID PEEK tubing. Fused silica capillaries of $363 \mu \mathrm{m}$ OD of 10 and $25 \mu \mathrm{m}$ ID were obtained from Polymicro Technologies (Phoenix, AZ, USA). Heating films (Minco, HK913-H, Distrelec, Nänikon, Switzerland), a fan (Sunon GM1203PHV2-8.GN, Farnell) and an electronic temperature sensor (Analog Devices, AD22103KTZ, Farnell) was used for thermostatting. The system was controlled via the Python based open-source software package Instrumentino [32, 33], running on a portable personal computer under Windows. The syringe pump and valves were connected to the personal computer via an electronic interface controller (EIB-200) from LabSmith, and the high voltage power supplies, the heating films and the temperature sensor via a purpose-made interface based on an Arduino microcontroller board (Arduino Nano 3.0, Distrelec). Communication between Instrumentino and the LabSmith parts was enabled by an application programming interface (API) from LabSmith running on the computer, and between Instrumentino and 
the parts connected to the Arduino board by a purpose written program running on the latter.

\subsection{Reagents}

All chemicals were of analytical grade and solutions were prepared with ultrapure water, purified using a Milli-Q system from Millipore (Bedford, MA, USA). Sodium chloride, potassium nitrate, potassium sulphate, potassium chloride, magnesium chloride, iron(II) sulphate, zinc sulphate and copper(II) chloride were purchased from Merck (Darmstadt, Germany). Manganese(II) sulphate, calcium chloride, lactic acid (Lac), citric acid, 18 crown-6 and ammonium chloride were purchased from Fluka (Buchs, Switzerland). LHistidine (His) and ultrapure nitric acid $\left(\mathrm{HNO}_{3}\right)$ were purchased from Sigma-Aldrich (Buchs, Switzerland) and acetic acid (HAc) was purchased from VWR (Dietikon, Switzerland).

\subsection{On-site sediment porewater measurements at Lake Baldegg}

Sediment cores were collected from the deepest part of Lake Baldegg (66 m) with a Uwitec gravity corer (Mondsee, Austria) equipped with a PVC tube $(6.5 \mathrm{~cm} \mathrm{ID,} 120 \mathrm{~cm}$ length). The PVC tube had pre-drilled holes (Ø $2 \mathrm{~mm}$ ) with $5 \mathrm{~mm}$ vertical spacing. The holes were sealed with adhesive tape prior to sampling. The sediment porewater was sampled directly after core retrieval with MicroRhizon filter tubes $(1 \mathrm{~mm}$ diameter and $0.20 \mu \mathrm{m}$ pore size) (Rhizosphere Research Products, Wageningen, Netherlands). 10 to 100 $\mu 1$ of porewater were extracted by horizontally inserting the MicroRhizon tubes through the taped holes. 


\section{$3 \quad$ Results and discussion}

\subsection{System design}

The overall design of the instrument is illustrated in Fig. 1 and a photograph is shown in Fig. 2. It features two separation channels fitted with negative and positive high-voltage power supplies for the concurrent separation of cations and anions in the same sample or two separate samples. Separate background electrolytes can be employed for the cations and anions to allow fully independent optimization of the separation conditions. Fluid handling is automated and based on a single miniature syringe pump and several valves to control aspiration and internal dispensing of background electrolytes and sample. Two modes of injection were implemented. Samples not limited in volume were aspirated fully automatically into the T-pieces in front of the capillaries from the sample container. This was achieved by opening all four valves to position B (as indicated in Fig. 1) and withdrawing the piston of the syringe pump (step I). However, the volume resolution of the syringe pump is not adequate for subsequent direct metering of the small samples volumes in the low nanolitre to picolitre range which need to be injected into the capillaries in the second step. Hydrodynamic injection in capillary electrophoresis is best handled by applying a controlled pressure for a controlled length of time. The conditions required for a desired injected volume for a given capillary diameter and length can then be calculated with the Hagen-Poiseuille equation. Previously for SIA-CE systems based on syringe pumps injection was achieved by pumping against a flow splitting manifold which created a desired backpressure [34-38]. Here, a different approach was adopted. For the second step of the sample injection the syringe pump was first partly filled with air by opening valve 2 to position A and further withdrawal of the syringe pump. The enclosed air was then compressed while keeping valve 2 in position C (closed)(step II). The desired pressure was achieved with the help of the electronic pressure sensor attached to the 
manifold and a control loop which is part of the software provided by the supplier of the parts. Once the pressure level was reached, valve 2 was turned to position B for the predetermined length of time while valves 3 and 4 were closed for the injection proper (step III). In step IV, valve 2 was closed and then valves 3 and 4 were opened to position $\mathrm{B}$ to release the pressure in the injection areas. Valve 1 was set to position A and the syringe was emptied to waste. After injection of the sample plugs BGE was aspirated to flush the manifold in front of the injection ends of the capillaries by opening valves 3 and 4 to position A and withdrawing the syringe pump, before the high voltage was turned on. Following the separation a final rinsing step was carried out to prepare for the next separation, which consisted of aspirating the BGEs and then flushing the capillaries for a sufficient amount of time.

Samples only available in small volume were aspirated directly into the opposite ends of the capillaries after placing these into the sample containers. The pressure sensor has a range from -100 to $800 \mathrm{kPa}$ relative pressure and thus by withdrawing the piston of the syringe pump it was also possible to precisely create the negative pressure relative to air required for sample injection from the far end of the capillaries. This step was carried out without air in the pump.

Separation and detection took place in an insulated and thermostatted compartment. Temperature directly affects the viscosity of liquids and thus several parameters in capillary zone electrophoresis with conductivity detection. The amount injected, as governed by the Hagen-Poiseuille equation, is thus dependent on temperature as is the electrophoretic mobility. Mobility not only has bearing on the migration times, but also on the peak areas as it affects the residence time in the detector cell. Furthermore, the 
conductivity, which also originates from the ionic mobility, has a temperature coefficient. While the ambient temperature in a laboratory is often fairly stable, this cannot be expected when working outdoors. In order to keep the volume and the thermal mass to be thermostatted small, temperature control was limited to the separation capillaries and the detectors. These were therefore contained in a separate compartment insulated with a 5 mm thick layer of cork. As it is easier to implement heating rather than cooling this was achieved with resistive heating and the temperature maintained with the help of an electronic temperature sensor and a software control loop (PID, proportional-integralderivative) running on the Arduino microcontroller board.

The high voltage part of the system, namely the buffer vials with the high voltage electrodes, was contained in two compartments made of poly-methylmethacrylate (PMMA) with the dimensions of $18 \times 16 \times 16 \mathrm{~cm}$ to provide sufficient space to preclude high-voltage discharges through the air. These are covered with a single lid which can be opened easily for small sample volume injection and other manipulations. It was fitted with a safety switch to prevent accidental exposure of the operator to the high voltage. Two separate buffer containers, which are connected with a short length of tubing, are used for each capillary to hold the capillary end and the high-voltage electrode. This approach prevents interference from electrolysis products and was first reported by de Jesus et al. [39].

The system was assembled in a briefcase with outer dimensions of $52 \times 34$ x $18 \mathrm{~cm}$, allowing easy transportation by a single person and the possibility to carry it as hand luggage on aircraft. Power is provided by rechargeable batteries or, where available, mains power can be used via adaptors. The batteries may also be recharged from the mains 
supply, but in order to allow work at remote locations a portable solar power panel was included in the system. This provides a maximum of $4.3 \mathrm{~A}$ at $17 \mathrm{~V}$ and has the dimensions of 137 x $48 \mathrm{~cm}$ when expanded, but a compact $31 \times 48 \mathrm{~cm}$ when folded for transport (weight $=2.25 \mathrm{~kg})$.

\subsection{Performance}

The effect of ambient temperature on the measurements and its alleviation by thermostatting was studied by performing electrophoresis experiments in the lab at temperatures of about $25^{\circ} \mathrm{C}$ and in a cooled room at a temperature of $10^{\circ} \mathrm{C}$. Three sets of determinations of $\mathrm{K}^{+}$were carried out: without thermostatting in a cold room and with thermostatting in both, the cold room and the laboratory. The resulting average migration times and peak areas for $\mathrm{K}^{+}$are shown in Fig. 3. As expected, the migration times obtained in the cold-room without thermostatting were about $40 \%$ longer than those recorded for the two thermostatted experiments. These gave very similar results (with the temperature control set to $27^{\circ} \mathrm{C}$ in both cases). A reduction of approximately $12 \%$ was obtained for the peak areas at the lower ambient temperature when thermostatting was not employed, while very similar results were obtained for the thermostatted experiments in the two environments. The prolonged migration time at the reduced temperature is expected to lead to an increase in peak area due to an extended residence time of the analyte plug in the detector. The fact that actually a decrease is observed must be caused by opposite temperature effects on the injection volume and the measurement of the conductivity signal. Thermostatting was thus found to be effective and it is expected to also work outdoors. Under hot ambient conditions the temperature control can also be set to a value above $27^{\circ} \mathrm{C}$. 
In Fig. 4 the electropherograms for cations and anions for a typical sample consisting of water from a drinking well are shown. These were acquired concurrently by making use of the dual channel facility of the instrument. Two different background electrolyte (BGE) solutions were employed for the separations of cations and anions. The BGE for the separation of the cations consisted of $9 \mathrm{mM}$ His, $4.6 \mathrm{mM}$ Lac, $25 \mathrm{mM}$ HAc and $1 \mathrm{mM} 18$ crown-6 (appr. pH 4.3), which had previously been shown to be suitable for simultaneous baseline separation of alkali, alkaline earth and transition metal cations through weak complexation [40]. For the anions a BGE consisting of $7.5 \mathrm{mM}$ His and $40 \mathrm{mM}$ HAc was adopted from a previous publication [19]. Electropherograms for a sample taken from the tailing pond of a mining operation are shown in Fig. 5. As the peak for the copper ion was found to be considerably delayed compared to the other analytes, the possibility of implementing pressure assisted capillary electrophoresis (PACE) in order to shorten the analysis time is demonstrated. The well water and the specimen from the tailing pond were collected during a sampling campaign carried out at the abandoned mining site Pan de Azúcar located in a remote area of the north western part of Argentina. The calibration data to allow quantification of the ions in these samples is given in Table I.

\subsection{Case study - sediment pore-water at Lake Baldegg}

Lake Baldegg is a $66 \mathrm{~m}$ deep eutrophic lake on the Swiss Plateau. Due to its relatively small hypolimnion volume and wind shielded geographic location the oxygen $\left(\mathrm{O}_{2}\right)$ concentration of the lake is critically sensitive to nutrient loads from the agriculturally dominated catchment. Deep-water anoxia has prevailed from the late $19^{\text {th }}$ century until today, and the lake is artificially aerated with molecular oxygen $\left(\mathrm{O}_{2}\right)$ during the stratification period [41]. Settling organic and inorganic particulate matter constitute the sediments of lakes. Fresh deposits are mineralized by microorganisms consuming organic 
matter thereby releasing a variety of reduced substances such as $\mathrm{NH}_{4}{ }^{+}, \mathrm{Fe}(\mathrm{II}), \mathrm{Mn}(\mathrm{II}), \mathrm{S}(-$ II), and methane. Oxygen, which is critical for all higher life forms in the deep water of lakes, is consumed at or near the sediment-water interface [42]. The determination of concentration profiles of the dissolved reduced components in the porewater of the top 10 to $20 \mathrm{~cm}$ of the sediment is of great interest to lake bio-geochemists to estimate areal flux rates, and hence consumption rates of $\mathrm{O}_{2}$ and the trophic state of lakes. Only small porewater volumes can be retrieved from the sediment in order to allow high spatial resolution and avoid bias of the local concentration gradients. Hence, a wide range of chemical parameters has to be analyzed in small sample volumes $(10-50 \mu \mathrm{L})$. This should be carried out immediately as sample conservation and transport often introduces a bias and bears the risk of contaminations.

Concentration profiles of cations and anions determined with the instrument in the field are shown in Fig. 6. Concentration gradients of dissolved substances which are consumed (such as the electron acceptors $\mathrm{NO}_{3}{ }^{-}$and $\mathrm{SO}_{4}{ }^{2-}$ ) or produced (such as $\mathrm{NH}_{4}{ }^{+}, \mathrm{Mn}(\mathrm{II})$ and $\mathrm{Fe}(\mathrm{II}))$ in the top 10 centimetres of the sediment are well pronounced. The electron acceptors $\mathrm{NO}_{3}{ }^{-}$and $\mathrm{SO}_{4}{ }^{2-}$ are consumed in the anoxic sediment and delivered from the lake bottom water with rates corresponding to their concentration gradients. Similarly, $\mathrm{Fe}(\mathrm{III})$ and $\mathrm{Mn}(\mathrm{IV})$ are used as electron acceptors for the mineralization of organic matter thereby releasing $\mathrm{Fe}(\mathrm{II})$ and $\mathrm{Mn}(\mathrm{II}) . \mathrm{NH}_{4}{ }^{+}$is a degradation product of organic amines and transported by molecular diffusion towards the sediment surface where it is eventually oxidized. Its production rate is directly proportional to the mineralization rate of organic matter in lake sediments. It is remarkable how well Fe(II) can be analyzed with the $\mathrm{CE}$ instrument since it is extremely sensitive to oxidation and reliable measurements in porewaters are otherwise very laborious (e.g. sediment extrusion in $\mathrm{N}_{2}$-filled glove bags 
and conservation). $\mathrm{Ca}^{2+}$ and $\mathrm{Mg}^{2+}$ are products of the dissolution of calcite and dolomite in the sediment as a consequence of decreasing $\mathrm{pH}$ due to the $\mathrm{CO}_{2}$ released during the mineralization of organic matter. Their concentration in lake water, however, is already high and thus no pronounced concentration differences develop between sediment porewater and lake bottom water. Chloride is an example of a conservative parameter that does not play a role in diagenetic processes. Fluxes of individual compounds and areal rates of their formation or consumption were determined by fitting the concentration profiles with a one-dimensional model that considered reaction and transport [43] and are presented in Table II. Reduced compounds diffusing from the sediment to the overlying water consume $\mathrm{O}_{2}$ in proportion $\left(\mathrm{NH}_{4}{ }^{+}\right.$consumes two equivalents of $\mathrm{O}_{2}, \mathrm{Mn}(\mathrm{II})$ and $\mathrm{Fe}(\mathrm{II})$ consume 0.5 and 0.25 equivalents, respectively) and thus areal fluxes as given in Table II help quantifying the sinks of $\mathrm{O}_{2}$ in lakes.

\section{Concluding remarks}

A dual-channel CE instrument with separate BGEs and a thermostatted compartment was constructed and demonstrated for the monitoring of inorganic ions in environmental water samples. The use of automated sample aspiration allowed the semiautomatic handling of small volumes of pore-water samples. The fact that the fluidic section was based on commercially available microfluidic parts allowed the easy construction of the system without sophisticated workshop facilities. The system is compact and can be carried by hand. It can be powered either from the grid or from batteries, which in turn can be recharged by solar cells, enabling the operation of the system in remote locations. For samples with low background conductivity it should be possible to implement sample stacking schemes (such as simple large volume injection) in order to achieve lower limits 
of detection. The broad applicability of $\mathrm{CE}-\mathrm{C}^{4} \mathrm{D}$ for ionic species makes this instrument also potentially useful outside environmental studies, such as for clinical or forensic tests, or for food analysis.

\author{
Acknowledgements \\ The authors are grateful for financial support by the Swiss National Science Foundation \\ through grants No. 200020-149068 and 200021-146234.
}

\title{
Conflicts of interest
}

The authors have declared no conflict of interest. 


\section{$5 \quad$ References}

[1] Kobrin, E.-G., Lees, H., Fomitsenko, M., Kubáň, P., Kaljurand, M., Electrophoresis $2014,35,1165-1172$.

[2] Hutchinson, J. P., Johns, C., Breadmore, M. C., Hilder, E. F., Guijt, R. M., Lennard, C., Dicinoski, G., Haddad, P. R., Electrophoresis 2008, 29, 4593-4602.

[3] Hutchinson, J. P., Evenhuis, C. J., Johns, C., Kazarian, A. A., Breadmore, M. C., Macka, M., Hilder, E. F., Guijt, R. M., Dicinoski, G. W., Haddad, P. R., Anal. Chem. 2007, 79, 7005-7013.

[4] Sáiz, J., Mai, T. D., Hauser, P. C., Garcia-Ruiz, C., Electrophoresis 2013, 34, 20782084.

[5] Kubáň, P., Seiman, A., Makarotseva, N., Vaher, M., Kaljurand, M., J. Chromatogr. A 2011, 1218, 2618-2625.

[6] Nguyen, H. T. A., Pham, T. N. M., Ta, T. T., Nguyen, X. T., Nguyen, T. L., Le, T. H. H., Koenka, I. J., Sáiz, J., Hauser, P. C., Mai, T. D., Sci. Justice 2015, 55, 481486.

[7] Mark, J. J. P., Kumar, A., Demattio, H., Hoffmann, W., Malik, A., Matysik, F. M., Electroanalysis 2011, 23, 161-168.

[8] Mai, T. D., Le, M. D., Sáiz, J., Duong, H. A., Koenka, I. J., Pham, H. V., Hauser, P. C., Anal. Chim. Acta 2016, 911, 121-128.

[9] Jayarajah, C. N., Skelley, A. M., Fortner, A. D., Mathies, R. A., Anal. Chem. 2007, 79, 8162-8169.

[10] Kumar, A., Burns, J., Hoffmann, W., Demattio, H., Malik, A. K., Matysik, F. M., Electrophoresis 2011, 32, 920-925.

[11] Nguyen, H. T. A., Pham, T. N. M., Doan, T. T., Ta, T. T., Sáiz, J., Nguyen, T. Q. H., Hauser, P. C., Mai, T. D., J. Chromatogr. A 2014, 1360, 305-311. 
[12] da Costa, E. T., Neves, C. A., Hotta, G. M., Vidal, D. T. R., Barros, M. F., Ayon, A. A., Garcia, C. D., do Lago, C. L., Electrophoresis 2012, 33, 2650-2659.

[13] Xu, Y., Wang, W., Li, S. F. Y., Electrophoresis 2007, 28, 1530-1539.

[14] Xu, Y., Li, S. F. Y., Electrophoresis 2006, 27, 4025-4028.

[15] Greguš, M., Foret, F., Kubán̆, P., J. Chromatogr. A 2016, 1427, 177-185.

[16] Ansari, K., Ying, J. Y. S., Hauser, P. C., de Rooij, N. F., Rodriguez, I., Electrophoresis 2013, 34, 1390-1399.

[17] Torres, N. T., Och, L. M., Hauser, P. C., Furrer, G., Brandl, H., Vologina, E., Sturm, M., Bürgmann, H., Müller, B., Environ. Sci.: Processes Impacts 2014, 16, 879-889.

[18] Torres, N. T., Hauser, P. C., Furrer, G., Brandl, H., Müller, B., Environ. Sci.: Processes Impacts 2013, 15, 715-720.

[19] Kubáň, P., Nguyen, H. T. A., Macka, M., Haddad, P. R., Hauser, P. C., Electroanalysis 2007, 19, 2059-2065.

[20] Kappes, T., Galliker, B., Schwarz, M. A., Hauser, P. C., TrAC, Trends Anal. Chem. 2001, 20, 133-139.

[21] Kappes, T., Hauser, P. C., Anal. Commun. 1998, 35, 325-329.

[22] Kappes, T., Schnierle, P., Hauser, P. C., Anal. Chim. Acta 1999, 393, 77-82.

[23] Lim, S., Nan, H., Lee, M.-J., Kang, S. H., J. Chromatogr. B 2014, 963, 134-139.

[24] Lee, M., Cho, K., Yoon, D., Yoe, D. J., Kang, S. H., Electrophoresis 2010, 31, $2787-2795$.

[25] Liu, P., Seo, T. S., Beyor, N., Shin, K.-J., Scherer, J. R., Mathies, R. A., Anal. Chem. 2007, 79, 1881-1889.

[26] Ryvolova, M., Preisler, J., Brabazon, D., Macka, M., TrAC, Trends Anal. Chem. 2010, 29, 339-353. 
[27] Lewis, A. P., Cranny, A., Harris, N. R., Green, N. G., Wharton, J. A., Wood, R. J. K., Stokes, K. R., Meas. Sci. Technol. 2013, 24, 042001 (20pp).

[28] Van Schepdael, A., Separations 2016, 3, 12.

[29] Sáiz, J., Mai, T. D., Koenka, I. J., Martin-Alberca, C., Hauser, P. C., Garcia-Ruiz, C., J. Chromatogr. A 2014, 1372, 245-252.

[30] Mai, T. D., Pham, T. T. T., Pham, H. V., Sáiz, J., Garcia Ruiz, C., Hauser, P. C., Anal. Chem. 2013, 85, 2333-2339.

[31] Koenka, I. J., Sáiz, J., Rempel, P., Hauser, P. C., Anal. Chem. 2016, 88, 3761-3767.

[32] Koenka, I. J., Sáiz, J., Hauser, P. C., Comput. Phys. Commun. 2014, 185, 27242729.

[33] Koenka, I. J., Sáiz, J., Hauser, P. C., Chimia 2015, 69, 172-175.

[34] Mai, T. D., Hauser, P. C., Talanta 2011, 84, 1228-1233.

[35] Mai, T. D., Hauser, P. C., Electrophoresis 2011, 32, 3000-3007.

[36] Mai, T. D., Hauser, P. C., J. Chromatogr. A 2012, 1267, 266-272.

[37] Mai, T. D., Schmid, S., Müller, B., Hauser, P. C., Anal. Chim. Acta 2010, 665, 1-6.

[38] Wu, C.-H., Scampavia, L., Rũžička, J., Analyst 2002, 127, 898-905.

[39] de Jesus, D. P., Brito-Neto, J. G. A., Richter, E. M., Angnes, L., Gutz, I. G. R., do Lago, C. L., Anal. Chem. 2005, 77, 607-614.

[40] Kubán̆, P., Kubáň, P., Kubáň, V., Electrophoresis 2002, 23, 3725-3734.

[41] Wehrli, B., Lotter, A. F., Schaller, T., Sturm, M., Aquat. Sci., 59, 285-294.

[42] Müller, B., Bryant, L. D., Matzinger, A., Wüest, A., Environ. Sci. Technol. 2012, 46, 9964-9971.

[43] Müller, B., Wang, Y., Dittrich, M., Wehrli, B., Water Res. 2003, 37, 4524-4532. 
Table I: Calibration Data

\begin{tabular}{|c|c|c|c|c|}
\hline Ion & $\begin{array}{c}\text { Calibration } \\
\text { Range } \\
(\mu \mathrm{M})\end{array}$ & $\begin{array}{c}\text { Reproducibility } \\
\text { of Peak Area } \\
(\% \mathrm{RSD}) *\end{array}$ & $\begin{array}{c}\text { Correlation } \\
\text { Coefficient, } \\
\mathrm{r}\end{array}$ & $\begin{array}{c}\text { LOD } \\
(\mu \mathrm{M})\end{array}$ \\
\hline $\mathrm{NH}_{4}^{+}$ & $5-150$ & 9.4 & 0.9988 & 4.8 \\
\hline $\mathrm{K}^{+}$ & $5-400$ & 10.5 & 1.0000 & 4.7 \\
\hline $\mathrm{Ca}^{2+}$ & $5-200$ & 8.2 & 0.9999 & 3.4 \\
\hline $\mathrm{Na}^{+}$ & $5-200$ & 11.6 & 0.9996 & 4.6 \\
\hline $\mathrm{Mg}^{2+}$ & $5-100$ & 10.0 & 0.9980 & 2.8 \\
\hline $\mathrm{Mn}^{2+}$ & $5-100$ & 9.1 & 0.9992 & 3.0 \\
\hline $\mathrm{Zn}^{2+}$ & $5-200$ & 6.4 & 0.9997 & 4.2 \\
\hline $\mathrm{Cu}^{2+}$ & $50-1000$ & 6.5 & 0.9840 & 18 \\
\hline $\mathrm{Cl}^{-}$ & $20-1000$ & 7.3 & 0.9998 & 11 \\
\hline $\mathrm{NO}_{3}{ }^{-}$ & $20-1000$ & 7.1 & 1.0000 & 12 \\
\hline $\mathrm{SO}_{4}{ }^{2-}$ & $20-1000$ & 6.3 & 0.9998 & 10 \\
\hline
\end{tabular}

* $\mathrm{n}=4$, determined at $100 \mu \mathrm{M}$ for the cations, $500 \mu \mathrm{M}$ for the anions 
Table II: Reaction-diffusion model fittings for datasets acquired with the CE instrument.

Areal fluxes of dissolved compounds from (negative values) and to (positive values) the sediment determined with a diagenetic reaction-diffusion model for the datasets.

\begin{tabular}{|l|c|}
\hline Parameter & Areal fluxes $\left(\mathrm{mmol} \mathrm{m}^{-2} \mathrm{~d}^{-1}\right)$ \\
\hline $\mathrm{NH}_{4}{ }^{+}$ & -3.0 \\
\hline $\mathrm{Mn}(\mathrm{II})$ & -0.22 \\
\hline $\mathrm{Fe}(\mathrm{II})$ & -0.67 \\
\hline $\mathrm{NO}_{3}{ }^{-}$ & 0.45 \\
\hline $\mathrm{SO}_{4}{ }^{2-}$ & 0.59 \\
\hline
\end{tabular}




\section{Figure Captions:}

Fig. 1 Schematic drawing of the overall configuration of the portable dual channel instrument indicating the two sample injection options.

Fig. 2 Photograph of the instrument. The syringe pump and valves are in the front, the thermostatted compartment in the centre and the high voltage compartments are to the right. All compartments have been opened.

Fig. 3 The effect of thermostatting on migration times and peak areas. Experiments were done in the laboratory and in a cold-room $\left(\mathrm{T}=10^{\circ} \mathrm{C}\right)$, with and without thermostatting to $27^{\circ} \mathrm{C}$. Sample: $\mathrm{KCl} 100 \mu \mathrm{M}$, BGE: HAc $500 \mathrm{mM}$. Capillary: $10 \mu \mathrm{m} \mathrm{ID,} \mathrm{45/60} \mathrm{cm} \mathrm{L} \mathrm{eff} / \mathrm{L}_{\text {tot }}$. Injection: $200 \mathrm{kPa}, 10 \mathrm{~s}$. Separation voltage: -30 $\mathrm{kV}$.

Fig. 4 Dual separation of (A) cations and (B) anions in a well-water sample. Capillaries: $25 \mu \mathrm{m} \mathrm{ID,} \mathrm{80/90} \mathrm{cm} \mathrm{L} \mathrm{L}_{\mathrm{eff}} / \mathrm{L}_{\text {tot. }}$ Injection: $20 \mathrm{kPa}, 10 \mathrm{~s}$. Separation voltage: $\pm 25 \mathrm{kV}$. The thermostat was set to $30^{\circ} \mathrm{C}$. BGE for cations: $9 \mathrm{mM}$ His, 4.6 mM Lac, $25 \mathrm{mM}$ HAc and $1 \mathrm{mM}$ 18-crown-6. BGE for anions: $7.5 \mathrm{mM}$ His and $40 \mathrm{mM}$ HAc.

Fig. 5 Cations in a sample from a mining pond (1:100 dilution), measured (A) without and (B) with pressure assistance. Capillaries: $25 \mu \mathrm{m} \mathrm{ID,} 65 / 80 \mathrm{~cm} \mathrm{Leff} / \mathrm{L}_{\text {tot }}$. Injection: $50 \mathrm{kPa}, 9$ s. Separation voltage: $-25 \mathrm{kV}$. Co-flow: $70 \mathrm{kPa}$ applied after 
375 s. BGE for cations: 9 mM His, $4.6 \mathrm{mM} \mathrm{Lac}, 25 \mathrm{mM}$ HAc and $1 \mathrm{mM}$ 18crown-6. BGE for anions: $7.5 \mathrm{mM}$ His and $40 \mathrm{mM}$ HAc.

Fig. 6 Depth profiles of major cations and anions in pore-water samples from a sediment core taken at Lake Baldegg. BGE: $11 \mathrm{mM}$ His, $50 \mathrm{mM}$ HAc, $1.5 \mathrm{mM}$ 18-crown-6 and $0.1 \mathrm{mM}$ citric acid. Capillaries: $25 \mu \mathrm{m} \mathrm{ID,} \mathrm{75/80} \mathrm{cm} \mathrm{L} \mathrm{L}_{\text {eff }} / \mathrm{L}_{\text {tot. }}$. Injection: $-30 \mathrm{kPa}, 11 \mathrm{~s}$. Separation voltage: $\pm 30 \mathrm{kV}$. 


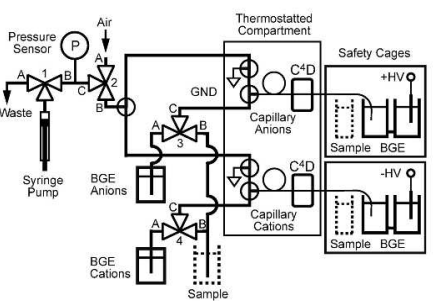

Figure 1

$276 \times 386 \mathrm{~mm}(300 \times 300$ DPI) 


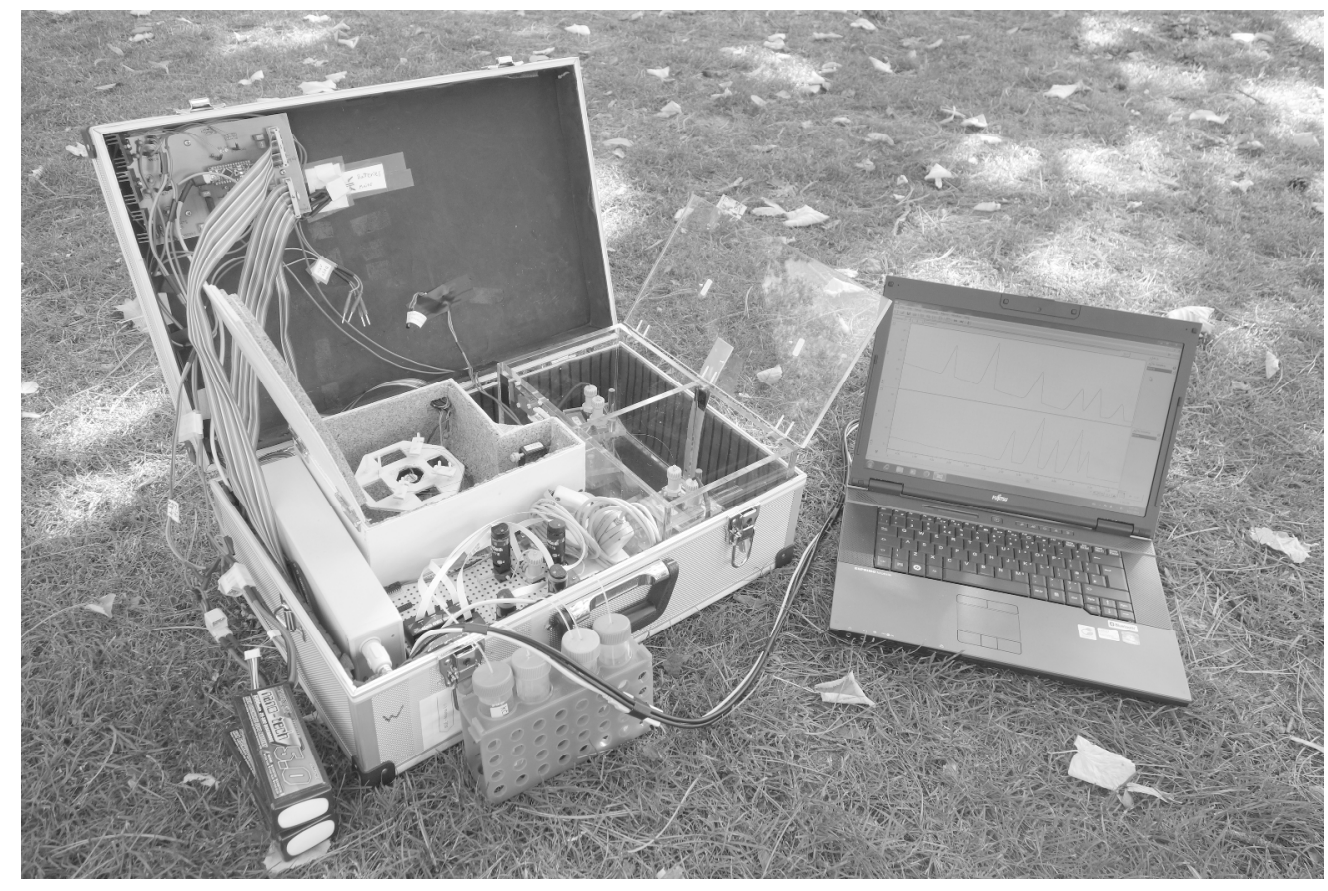

$264 \times 176 \mathrm{~mm}(300 \times 300$ DPI $)$ 


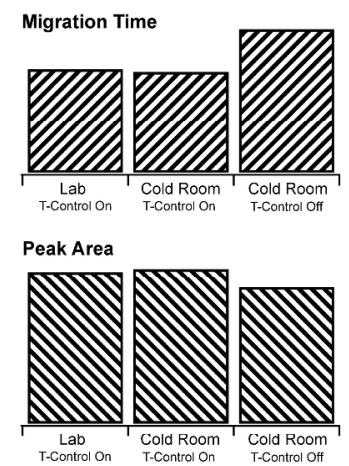

Figure 3 

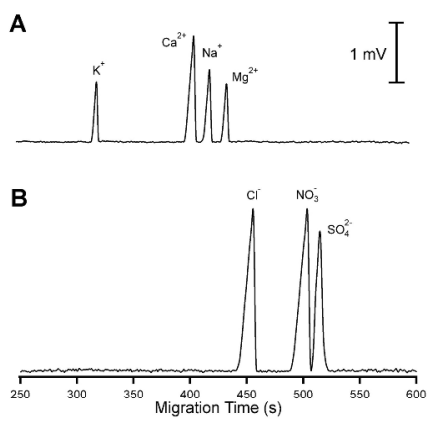

Figure 4 $276 \times 386 \mathrm{~mm}(300 \times 300$ DPI $)$ 


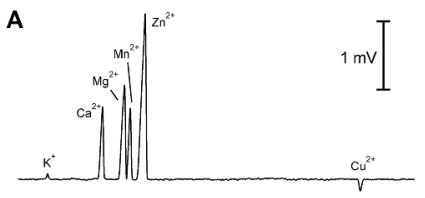

B

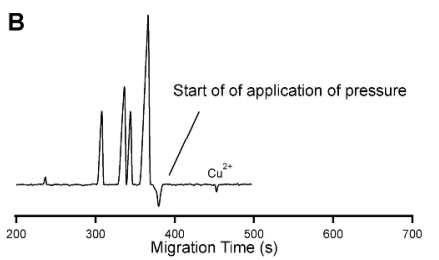

Figure 5

$276 \times 386 \mathrm{~mm}(300 \times 300$ DPI) 


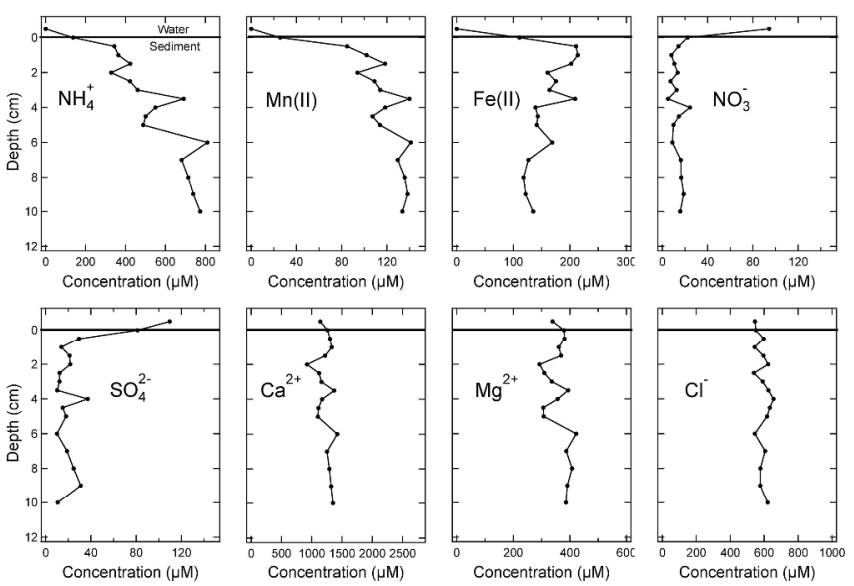

Fig. 6

$276 \times 386 \mathrm{~mm}(300 \times 300$ DPI $)$ 